\title{
The predicted growth of the low Earth orbit space debris environment - an assessment of future risk for spacecraft
}

\author{
P.H. Krisko \\ ESCG/Jacobs, 2224 Bay Area Blvd., Houston, TX, 77058 \\ paula.krisko-1@nasa.gov
}

\begin{abstract}
:
Space debris is a worldwide-recognized issue concerning the safety of commercial, military, and exploration spacecraft. The space debris environment includes both naturally occuring meteoroids and objects in Earth orbit that are generated by human activity, termed orbital debris. Space agencies around the world are addressing the dangers of debris collisions to both crewed and robotic spacecraft. In the United States, the Orbital Debris Program Office at the NASA Johnson Space Center leads the effort to categorize debris, predict its growth, and formulate mitigation policy for the environment from low Earth orbit (LEO) through geosynchronous orbit (GEO).
\end{abstract}

This paper presents recent results derived from the NASA long-term debris environment model, LEGEND. It includes the revised NASA sodium potassium droplet model, newly corrected for a factor of two over-estimation of the droplet population. The study indicates a LEO environment that is already highly collisionally active among orbital debris larger than $1 \mathrm{~cm}$ in size. Most of the modeled collision events are non-catastrophic (i.e., They lead to a cratering of the target, but no large scale fragmentation.). But they are potentially mission-ending, and take place between impactors smaller than $10 \mathrm{~cm}$ and targets larger than $10 \mathrm{~cm}$. Given the small size of the impactor these events would likely be undetectable by present-day measurement means. The activity continues into the future as would be expected. Impact rates of about four per year are predicted by the current study within the next 30 years, with the majority of targets being abandoned intacts (spent upper stages and spacecraft). Still, operational spacecraft do show a small collisional activity, one that increases over time as the small fragment population increases.

\subsection{Introduction}

The growth of orbital debris in low Earth orbit (LEO) and beyond has continued since the beginning of the space age. The launching into orbit and abandonment of spent satellites (i.e., upper stages and spacecraft (payloads)) at end-of-life has certainly contributed to that growth. However, more insidious sources such as accidental explosions of satellites and release of material or objects by design or accident have contributed to much higher fluxes of orbiting debris over the years. Though these objects are generally much less massive than their intact parents, they still represent dangerous possible impactors. Existing international programs of orbital debris study are dedicated to impact testing with accompanying simulations [1-3], remote and in-situ measurements of the near-Earth environment [4-9], and debris environment modeling [10-27]. National safety standards with respect to the protection of spacecraft from 
orbital debris impacts have grown around these research efforts [28-31]. Recognizing the issue as international has led to cooperation in the study of space debris through the Inter-agency Space Debris Coordination Committee (IADC) and the United Nations (UN), and to international debris mitigation standards [32,33].

This paper describes the issue of orbital debris and past work on modeling efforts of the LEO debris environment. It presents current results of a study encompassing the historical period through the near future. It confirms that the inclusion of smaller debris objects (down to $1 \mathrm{~cm}$ ) in the calculation of collision rates among objects in LEO may be necessary to better understand the dangers of the environment.

\subsection{Debris Identification -- Known Sources}

The space debris environment includes both naturally occuring meteoroids and objects in Earth orbit that are generated by human activity. The spatial extent of the environment ranges from LEO (200 km through $2000 \mathrm{~km})$ well past GEO (33,000 km through 39,000 km), though the current interest extends generally up to the GEO region. These orbiting human-made objects are termed orbital debris and include objects from sub-microns to meters in cross section. Known sources of orbital debris in LEO include the following,

- $\quad$ spent intact satellites past end-of-life,

- mission-related debris (i.e., objects released in the course of spacecraft deployment and operations),

- fragments of intact satellites resulting from accidental or intentional explosions and collisions,

- radiator coolant droplets (i.e., sodium potassium, NaK) from re-orbited and ejected RORSAT nuclear cores,

- solid rocket motor exhaust products,

- ejecta from micro-particle impacts with intact satellite and fragment surfaces,

- $\quad$ and paint flakes (i.e., intact satellite and fragment surface degradation products).

For the most part the sources of space debris span the size regimes noted in Table 1. Naturally occurring meteoroids display a terrific range in sizes due to their sources, asteroidal and cometary dust and fragments [34]. But it must be remembered that for both meteoroids and orbital debris the particle size and flux are negatively correlated. As for meteoroids larger than $1 \mathrm{~cm}$, they are much less populous in LEO than orbital debris as shown in Figure 1.

The fragmentation or breakup process is responsible for over $60 \%$ of all cataloged objects in LEO today (i.e., the greatest source of larger than 10-cm debris). In particular, accidental propulsion-related explosive events involving upper stages have been confirmed in 85 breakup events of a total of 190 to date, and are the most important source of the present-day fragment population. Other sources of fragmentation include spacecraft battery explosions, deliberate explosions or collisions, accidental on-orbit collisions, anomalous breakups, and breakups with unknown causes 
[35]. Fragmentation debris has the largest range in size (sub-micron through tens of meters).

Only three accidental collisions between cataloged objects from different missions have been verified. Earlier work in debris studies foresaw the advent of accidental collisions becoming a major source of debris and a grave danger to operational spacecraft in the future. The collision process has been studied through on-orbit events and empirical calculations [36,37], and controlled ground tests [1-3]. Collisions termed 'catastrophic' result in the complete fragmentation of impactor and target (impactor mass is smaller than target mass by definition). This has been shown to occur empirically when the impact energy per target mass exceeds $40 \mathrm{~J} / \mathrm{g}$,

$$
0.5 * \mathrm{M}_{\text {impactor }} * \mathrm{~V}_{\text {impact }}{ }^{2} / \mathrm{M}_{\text {target }}>40 \mathrm{~J} / \mathrm{g}
$$

Collisions are 'non-catastrophic' if the above conditions are not met. Here the impactor is destroyed and the target is cratered, and though this can lead to an end-of-mission of an operating spacecraft, it does not generally result in a large number of lethal fragments being released into the environment.

Another source identified in the early 1990s is a population of sodium potassium (NaK) droplets. These were caused by Soviet RORSAT vehicle nuclear reactor ejections through the 1980s. This source has been studied extensively [38-43]. The droplets were leaked through opened radiator tubing and formed nearly spherical shapes while in their initial liquid form. They are believed to range in diameter from about $0.5 \mathrm{~mm}$ to over 5 $\mathrm{cm}$, and are easily identifiable by their polarized radar signatures [4]. Their shape and density give them a relatively small area-to-mass ratio and a low orbital decay rate. The number larger than $1 \mathrm{~cm}$ is estimated to be about 20,000. Given the altitudes of ejection (most events at $900 \mathrm{~km}$ to $1000 \mathrm{~km}$ ), most of these are still in orbit and will remain so for decades.

The combustion products of solid rocket motor (SRM) firings are also known debris sources. Major uses of SRMs have historically been as LEO-to-GTO (geosynchronous transfer orbit) boosters and as GTO-to-GEO circularizers [44,45]. Aluminum oxide $\left(\mathrm{Al}_{2} \mathrm{O}_{3}\right)$ included as an additive in the propellant escapes the chamber as dust during burn and as much larger particles at the end of burn. Particles are estimated to range in size from $100 \mu \mathrm{m}$ dust to $5 \mathrm{~cm}$ 'slag' or 'char' [46].

Other sources in the micron to hundreds of micron range include ejecta caused by micro-particle impacts on larger surfaces and paint flaking or surface degradation due to aging of materials in space $[47,48]$.

\subsection{Debris Measurements}

The United States Space Surveillance Network (SSN) comprises a family of radar systems dedicated to the cataloging (i.e., reliable tracking) of orbiting objects. Though other groups possess cataloging systems in various stages of advancement [49-51], the 
SSN is still the main source of information of objects generally considered to be larger than $10 \mathrm{~cm}$ in average cross section in LEO. The cataloged objects in LEO orbit currently number over 9000. The sources of orbital debris of this size are primarily spent intact satellites, mission-related debris, fragmentation debris, and a few larger NaK droplets. Recently, radar systems of shorter wavelength and high power have begun to bring this minimum tracked size down to $5 \mathrm{~cm}$ but coverage is still very limited [52].

Smaller debris, larger than about $1 \mathrm{~cm}$ but smaller than $10 \mathrm{~cm}$ in average cross section, must be viewed statistically. This is currently done most efficiently with ground-based radar systems. In the United States, the Haystack and Haystack Auxiliary (HAX) radars have been the primary viewers of objects to about $5 \mathrm{~mm}$ and $1 \mathrm{~cm}$, respectively, in LEO since the early 1990s [4,5]. With estimated numbers in the hundreds of thousands it is unlikely that objects of this size will ever be fully tracked and cataloged. There are three major known sources of this debris. The most numerous and widely distributed is again debris from on-orbit breakups. The others are NaK droplets and SRM slag.

Yet smaller debris, on the order of microns to several millimeters, can currently only be reliably sampled in-situ. That is surfaces returned from space have been examined for these micro-particle impacts. Regular inspections of the NASA Space Shuttle selected surfaces are performed after each mission [6,7] . Returned Hubble Space Telescope (HST) solar panels yield impacts [8]. Surfaces from missions dedicated to impact studies such as LDEF and EURECA have also been recovered and analyzed [9]. These data represent the limits of human observation of debris. Though it is reasonable to assume that smaller debris exists, they are perhaps swamped by the meteoroid environment. But with the threshold of observation is also the threshold of concern for most space activities (The Space Shuttle and ISS have critical surfaces vulnerable to a few millimeter-sized objects, Extra Vehicular Activity (EVA) suits are vulnerable to $200 \mu \mathrm{m}$ debris.)

\subsection{Orbital Debris Models}

Worldwide efforts to categorize the debris environment, through radar and optical measurements on the ground, debris-collecting experiments (in-situ) in orbit, and ground impact tests are paralleled by modeling efforts. These programs make use of the measurement data and simulate debris populations in the past, current, and future environment.

There are several emphases in modeling that have evolved in the orbital debris field. In order of shortest-to-longest time scale modeling, the first is collision risk assessment to valuable orbiting assets (e.g., For NASA the International Space Station and Space Shuttle are the primary assets.). One set of impactors of concern are other cataloged objects. Risk of orbit conjunction is determined via covariance information provided by cataloging agencies [10,11]. Another concern to space assets are uncataloged fragments from recent breakups. The evolution of a debris cloud is of primary importance here. In LEO a cloud becomes randomized in argument of perigee and right ascension of 
ascending node within a few months or years after creation. The days to weeks after breakup can see a dense pack of hundreds of thousands of fragments larger than $1 \mathrm{~mm}$ that, if passing through the orbit of a space asset, could present a high probability of collision. Specialized risk analysis codes have been designed for the purpose of statistically analyzing risk from young debris clouds [12-15].

Engineering models are designed to provide accurate results, in a timely fashion, of the debris environment that will be encountered by a spacecraft in the present and nearfuture (i.e., on time-scale of decades). These models, which are publicly available, are often used by spacecraft designers and operators, and debris observers [16-18]. These models have also served as base debris flux models for other programs, such as various high-fidelity spacecraft risk analysis codes $[19,20]$ and mitigation policy compliance codes [21,22].

Long-term debris environment models, which contribute to the engineering model environments, are most pertinent to this paper. These models generally encompass timeframes in the distant future, with 100-year projection periods being the norm. The premise of these models is to extend recent launch and debris generation rates to estimate the future growth of the debris environment. The main uncontrolled aspect of the future environment appears to be accidental collisions. A 10-cm lower limit to the sizes of the impactors and targets in the collision calculations has been adopted by all long-term models [23-27]. The main reasons for this have been the constraints of computing time and memory size, and more importantly, the realization that it is these collisions between larger objects that are most likely to result in fragments, also larger than $10 \mathrm{~cm}$, which will become dangerous impactors themselves. Given the statistical nature of future collision events, all models also apply Monte Carlo processing to the future environment, so that the average collision rate can be discerned from an ensemble of futures. The historical period, which is, of course, well understood (in the $10-\mathrm{cm}$ population), is taken as the initial condition for all futures.

Long-term studies require several choices of future activities, that of naturally occuring phenomena such as solar flux, atmospheric density and scale height, and that of human endeavors, such as launch rates, insertion altitudes of choice, and new spacecraft technology. Cyclical natural phenomena are generally tied to the past [53]. The prediction of human activity in space within the next decade is very difficult, let alone predictions over centuries. But as in other fields (e.g., climate and population predictions) the purpose of the long-term debris environment model is to attain a prediction of future events assuming certain practices remain in place. Results of such studies then become the basis for policy decisions. Already, long-term debris environment modeling has influenced national and international safety standards regarding debris generation and intact payload and upper stage safing as noted previously in this paper.

\subsection{History of Long-term Debris Environment Modeling at NASA}


NASA has a long history of modeling the debris environment beginning in the late 1970s amid concerns for crew safety. Simplified stand-alone breakup models and orbital propagators that included the lowest order terms in gravity and drag were developed. By the late 1980s NASA initiated the EVOLVE series of programs which applied Monte Carlo processing to estimate future fragmentations for the first time. Five distinct versions of the EVOLVE code were completed over the next decade. All were 1-dimensional models in LEO in the sense that collision events were assigned within spherical altitude shells from $200 \mathrm{~km}$ altitude to $2000 \mathrm{~km}$ altitude.

Advances in the supporting models within EVOLVE were driven by added observational data. For the fragmentation model this meant a longer period of object decay profiling during high and low solar activity and additional ground breakup test data. The main result was a fragment area-to-mass distribution for each size range; an advance beyond the spherical fragment modeling of the past [54]. A new orbital element propagator was developed by comparing predicted decay files and long-term orbital evolution to actual ones of a number of intact objects in orbit [55]. This led to the addition of higher order gravity terms, an oblate Earth, a rotating atmosphere, advanced lunar and solar gravity effects, and solar radiation pressure effects with Earth shadowing. Other advances included fragment initial $\Delta \mathrm{V}$ distribution and traffic file upgrades [56].

The final version of the EVOLVE model included the new propagator and a tagging of collision pairings by type: intact-on-intact, intact-on-fragment, fragment-on-fragment. Still, EVOLVE remained a 1-dimensional model in the collision calculation. This restricted the fidelity of the collisional breakup pairings since only pair type could be identified, not individual objects.

The model LEGEND (LEO-to-GEO Environment Debris model) was developed in the early 2000s to address the above concerns and is now the standard NASA model for long-term orbital debris environment studies. LEGEND includes the traffic, breakup, and LEO propagator models of the final EVOLVE model, but also a geosynchronous orbital element propagator that extends the range of this model. The 3-dimensional character of LEGEND is realized in the propagators noted above, and in the consideration of collision pairs individually. This is done through an efficient 3dimensional algorithm for collision pairing in altitude, longitude, and latitude [56]. This type of calculation requires a much higher level knowledge than has been needed in the past of launch and maneuver traffic, and also fragmentation orbital position of historical events. This is an ongoing priority for the historical launch and fragmentation event files that are inputs to LEGEND.

The supporting computer models of LEGEND include the 2001 NASA Standard Breakup Model, the 3-dimensional propagators for non-GEO and GEO orbits, and the RORSAT sodium potassium droplet model. Supporting input files for the historical environment include a set of yearly historical launch traffic and fragmentation event files and NOAA solar flux files. The future environments require projected versions of models of solar flux, launch traffic, and satellite explosion rates. 
At this time the LEGEND package does not include models for SRM slag, ejecta, or paint flake generation and propagation. These are important sources of debris and work is progressing on their study. However, the main purpose of LEGEND has been defining environmental growth due to orbit insertions and fragmentations into the distant future. It is the included sources that have been shown to populate the environment with large objects (i.e., $\geq 10 \mathrm{~cm}$ ), objects that can be considered as dangerous impactors. And it is this model, which is adapted for the work reported here.

\subsection{Debris Environment and Risk to Spacecraft}

This paper explores the risk to robotic spacecraft due to orbital debris. As noted above many long-term studies have been completed on this subject, but the present study extends the work in two directions. First this study investigates collision rates among objects larger than $1 \mathrm{~cm}$. The previous lower limit among all long-term modeling projects is objects larger than $10 \mathrm{~cm}$ in size. The $10-\mathrm{cm}$ limit was chosen historically for two reasons, 1) to allow timely calculations over long-term studies with existing computer systems, and 2) because these larger objects have always been considered most important to evaluate since their fragmentation was deemed most likely to generate large fragments that would themselves become dangerous impactors. But recent observations have indicated that there could be a small number of collisions involving small impactors (i.e., $<10 \mathrm{~cm}$ ) and large targets (i.e., $\geq 10 \mathrm{~cm}$ ) that have already taken place [57]. And there is the knowledge that a small impactor can cause a catastrophic fragmentation of a spacecraft [2].

Second, while previous studies have performed the risk analysis within the future environment of 100 years or more, this paper includes the past in the analysis period and limits the future period through year 2035. This provides an opportunity to combine the past environment, formed by known launches and explosion events, with a statistical derivation of possible collision events during that time. It brings confidence

to the modeling process and provides a smooth transition between the known past environment and the near-term future.

The projection limit of about 30 years is routinely used in engineering models for the purpose of providing users with environments that show growth, but are close enough to the present so that technology advancements and changes in mitigation measures can be justifiably deemed minor. Thus the future period through 2035 in this study is considered to reasonably adhere to today's launch rates, insertion altitude choices and mitigation practices.

The mitigation standards or guidelines in place in LEO today focus on several points,

- the safing of upper stages and spacecraft at end-of-life (e.g., the evacuation of fuel and oxidizer tanks and lines, the decoupling of batteries),

- the limiting of mission-related debris, and 
- the reduction of upper stage and spacecraft perigee altitudes at end-of-life to assure a 25-year or less orbital lifetime.

Some of these points are implemented partially. For example, while upper stage safing and elimination of mission-related debris is a desired procedure in the United States, compliance is not yet mandatory for all programs. The same is true in Europe. The 25year de-orbit rule has, so far, been implemented sparingly, even among government programs.

\subsection{Study Parameters and Analysis}

NASA's long-term debris environment model LEGEND was adapted for this work. Summaries of model parameters, specific to this study, are listed in Table 2. The chosen launch traffic is from the 8-year period, 1999 through 2006. Crewed vehicles and associated mission-related debris is not included in this study. Spacecraft of three constellations launched in the historical period are given 8-year operating periods, and then disposed of according to each plan. These constellation spacecraft are not launched in the projection period, nor are their upper stages. Other (non-constellation) spacecraft are considered operational for 5 years after orbit insertion. This has been the general historical rule for spacecraft in LEO [58]. In addition, upper stages are considered spent immediately after orbit insertion.

The sources of debris available to LEGEND at this date include spent upper stages and spacecraft, mission-related debris, explosion and collision fragments, and $\mathrm{NaK}$ droplets. Breakup events contribute the great majority of objects in LEO larger than $1 \mathrm{~cm}$, over 99\%. In the historical period of this study (1957 through 2006) verified explosion and collision events are assigned as they occur. Additional accidental collision events among 1-cm and larger objects (i.e., debris and NaK droplets) are determined statistically. Event assignment through the pair-wise comparison of object positions in 5-day intervals is described in [59] and references therein. All future events are determined statistically. For explosions, families of intacts are graded by history of accidental explosions and recent trends of safing, and assigned probabilities of explosion accordingly. The frequency of accidental collisions between objects larger than $1 \mathrm{~cm}$ is determined as noted in the historical period.

Fragments created by the described events are deposited via a version of the NASA Standard Breakup Model. Those larger than $1 \mathrm{~cm}$ are treated as potential impactors. Non-catastrophic collisions, which generally fragment the small impactor and crater the much larger target create few if any 1-cm or larger fragments.

SRM slag, ejecta, and paint flakes are known to be produced in the near-Earth environment. But they are not included as debris here, as NASA currently has no validated models for these sources. However, the present study is concerned with the larger than 1-cm population as a collision source. Only SRM slag could be large enough in size to contribute to the collision rate. So, as a caveat to this work, it must be 
noted that the inclusion of a SRM slag model would most likely increase the collision rates calculated.

Those collision rates are averaged over 200 Monte Carlo iterations of the LEGEND process and tabulated in Table 3. To summarize a few main points, the averaged LEGEND result with the stated study parameters shows that during the study period,

- During the historical period collisions between two objects larger than $10 \mathrm{~cm}$ (i.e., two cataloged objects), occur with an average rate on the order of what has been observed (i.e., three in the last 50 years).

- By the end of the projection period collisions between objects larger than $10 \mathrm{~cm}$ have occurred with an average rate that is similar to that of previous NASA studies [59].

- The number of collisions among 1-cm and larger objects passing through LEO is nontrivial at present in the future.

- Collisions between small impactors $(<10 \mathrm{~cm})$ and large targets $(\geq 10 \mathrm{~cm})$ make up nearly $95 \%$ of all events.

o Of these events, about $98 \%$ are non-catastrophic.

o Of these events, NaK droplets make up between 16\% (end of historical period) and $13 \%$ (end of projection period) of the impactors, the remainder being fragments. This relative rate appears to be dropping over time.

o Of these events, between $5 \%$ and $9 \%$ involve targets that are operational spacecraft. This relative rate appears to be dropping over time.

- Nearly 5\% of all collision events are catastrophic.

o Of those events, $30 \%$ involve small impactor on large target pairings.

The majority of these modeled events would be unlikely to be observed -- noncatastrophic events occurring between what would be un-cataloged small impactors and cataloged targets. A more detailed view is presented in Table 4 . In over $90 \%$ of these cases the target is an intact object (i.e., an upper stage, spacecraft, or mission-related debris). Operational spacecraft populate a small subset of these targets, amounting to about 5\%. So it is the population of large abandoned intacts in LEO that serve as the main targets for small debris, and this activity is not trivial in occurrence. Though largely undetected, such impacts have been recently suggested by the study of a few 'anomalous events', which resulted in slight ephemeris changes of intact objects [60].

The modeled overall collision rate continually increases over time towards a rate of four events per year by the end of the analysis period (Figure 2). The larger than $1 \mathrm{~cm}$ $\mathrm{NaK}$ collision rate appears to stabilize after the final deposit of droplets in 1989 to a nearly constant rate. According to this study, a rate of about one NaK impact every four years would be expected at least through 2035.

Figures 3 and 4 further categorize the activity by LEO altitude. NaK droplets account for about $16 \%$ of all events by the end of the year 2006 and are of course found in the altitude regions $800 \mathrm{~km}$ through $1050 \mathrm{~km}$ where the droplets are clustered at that date. 
The overall collision rate within the altitude range $950 \mathrm{~km}$ through $1050 \mathrm{~km}$ is significantly increased due to the NaK. By the end of the year 2035 general collision events have increased nearly fourfold and spread in altitude range. NaK droplets, in particular, continue to affect the collision rates of lower altitudes as they decay out of orbit.

Particular target and impactor characteristics are depicted in Figures 5 and 6. Catastrophic collision events tend to occur between objects of similar size and mass, while the non-catastrophic events are likely with impactors that are much smaller and less massive than their targets. This is expected from the energy-to-mass ratio noted in Equation 1 for catastrophic collisions. In cases where this mass relationship does not hold, a very high or low impact velocity dominates the event. Impact velocities in LEO can range between $100 \mathrm{~m} / \mathrm{s}$ to over $15 \mathrm{~km} / \mathrm{s}$ depending on the target and impactor orbits and orientations of impact. Vertical striations towards the right in both Figures 5 and 6 show particular intact targets or families of targets that are collisionally active in the model. For example in Figure 6, the target points at $8300 \mathrm{~kg}$ are Russian Zenit upper stages, which have a $41 \mathrm{~m}^{2}$ average cross sectional area and populate high inclinations $\left(\geq 65^{\circ}\right)$ and altitude ranges, mostly from $600 \mathrm{~km}$ through $900 \mathrm{~km}$. The target characteristic lengths (masses) to the left in Figures 5 and 6, respectively, show no striations. This is because they are smaller (lighter) fragments, and therefore irregular in size and mass.

\subsection{Summary and Conclusions}

This work was performed with the NASA long-term debris environment model, LEGEND, adapted for the prediction of collisions among objects larger than $1 \mathrm{~cm}$. The NASA Standard Breakup Model deposited the fragments of the calculated explosions and collisions. NaK (sodium potassium) droplets were generated by the NASA NaK model, newly corrected for a factor of two over-estimation of the droplet population. Solid rocket motor (SRM) slag and surface degradation particulates (ejecta and paint flakes) were excluded in this work. NASA, at present, has no verified models of either. The only known source of $1 \mathrm{~cm}$ objects would be the SRM slag, which would then likely increase the collision rates determined here. Also excluded were any vehicles or mission-related debris associated with crewed missions. This work was intended as a general study of collision risks in the high traffic regions of LEO.

This study models collisional events among objects in LEO larger than $1 \mathrm{~cm}$ throughout the years 1957 through 2035. The activity occurs in regions of high traffic in LEO, the altitude bands $600 \mathrm{~km}$ to $1000 \mathrm{~km}$ and $1400 \mathrm{~km}$ to $1500 \mathrm{~km}$. The risk to LEO spacecraft in the near future is a continuation of that which has been occurring throughout the past. The overall effect is an increasing collision rate to a handful of events per year by the end of 2035, this assuming only standard mitigation techniques are applied throughout the period (e.g., moderately successful upper stage safing and mission-related debris suppression as in the last decade). 
Non-catastrophic collisions between small impactors $(<10 \mathrm{~cm})$ and large targets $(\geq 10$ $\mathrm{cm}$ ) are by far the dominant mode of collisions in the modeled environment. In reality these events would be unlikely to be observed, as the effect is a destruction of an untracked impactor and some crater damage to a much larger target.

The only objects in the study generally smaller than $10 \mathrm{~cm}$ are NaK droplets and most of the breakup fragments. It is the fragment population that dominates the impactors. And that population continues to grow throughout the study through statistically determined explosions and catastrophic collisions. Meanwhile, the static population of NaK droplets decays in orbit. This results as a decrease over time in the percentage of $\mathrm{NaK}$ droplet collision events with respect to the total number.

The targets of these events are found mostly in the population of abandoned intacts. Families of spent upper stages and spacecraft are identifiable in this analysis as likely participants. There is a much smaller collision rate associated with operating spacecraft. But the conditions of the study -- the general 5-year operational lifetimes for spacecraft (8-year for constellation spacecraft) and the 8-year cyclic launch rate - limit the operational spacecraft activity with respect to the ever-growing number of abandoned intacts. Still a non-catastrophic impact on an operational spacecraft could compromise the mission. The rate of catastrophic events shows a slower growth than that among objects larger than $10 \mathrm{~cm}$. But, the small impactor would be less likely to be detected.

\section{Acknowledgements:}

The author wishes to acknowledge Mr. Nicholas Johnson of the NASA/JSC Orbital Debris Program Office for his comments and advice during the writing of this paper. 


\section{References}

1. Bess TD. Mass distribution of orbiting man-made space debris. NASA Technical Note D-8108. NASA. Washington D.C. USA, December 1975.

2. McKnight DS, Johnson NL, Fudge ML, et al. Satellite orbital debris characterization impact test (SOCIT) series data collection report. NAS 9-19215, April 1995.

3. Fucke W, Sdunnus H, Klinkrad H. Population model of small size space debris. Final Report, ESOC Contract No. 9266/90/D/MD, June 1993.

4. Stokely CL, Foster JL, Stansbery EG, et al. Haystack and HAX radar measurements of the orbital debris environment; 2003. NASA/JSC-62815, November 2006.

5. Stokely CL, Foster JL, Stansbery EG, et al. Haystack and HAX radar measurements of the orbital debris environment; 2003 Appendix A. NASA/JSC-62815A, November 2006.

6. Hyde J. As flown shuttle orbiter meteoroid/orbital debris assessment, Phase I Shuttle/Mir missions: STS 71, 76, 79, 81, 84, 86, 89 \& 91. NASA/JSC-28768, January 2000.

7. Hyde J. As flown shuttle orbiter meteoroid/orbital debris assessment, Phase II flights: STS-50, 56, 72, 73, 75, 77, 80, 85, 87, 88, 94, 95, \& 96. NASA/JSC29070, September 2000.

8. Drolshagen G, McDonnell JAM, Stevenson T, et al. Post-flight measurements of meteoroid/debris impact features in EURECA and the Hubble solar array. Advances in Space Research. 1995; 16(11): 85-89.

9. Zolensky ME, See TH, Bernhard RP, et al. Final activities and results of the long duration exposure facility meteoroid and debris special investigation group. Advances in Space Research, 1995; 16(11): 53-65.

10. Foster JL. The analytic basis for debris avoidance operations for the International Space Station. Proceedings of the 3rd European Conference on Space Debris. ESA, 2001: 441-446.

11. Alarcon JR, Klinkrad H, Cuesta J, et al. Independent orbit determination for collision avoidance. Proceedings of the $4^{\text {th }}$ European Conference on Space Debris. ESA, 2005: 331-336.

12. Matney MJ, Theall JR. The use of the satellite breakup risk assessment model (SBRAM) to characterize collision risk to manned spacecraft. IAA-99-IAA6.5.09, $50^{\text {th }}$ International Astronautical Congress, Amsterdam The Netherlands, 1999.

13. Jenkin AB. Probability of collision during the early evolution of debris clouds. Acta Astronautica. 1996; 38(4-8): 525-538.

14. Barrows SP, Swinerd GG, Crowther R. Review of debris cloud modeling techniques. Journal of Spacecraft and Rockets. 1996; 33(4): 550-555.

15. Theil S, Westerkamp R. The short-term and long-term collision risk caused by fragmentation clouds. Proceedings of the $2^{\text {nd }}$ European Conference on Space Debris. ESA, 1997: 625-627. 
16. Liou J-C, Matney MJ, Anz-Meador PD, et al. The new NASA orbital debris engineering model ORDEM2000. NASA/TP_2002-210780, May 2002.

17. Oswald M, Wegener P, Stabroth S, et al. The MASTER 2005 model. Proceedings of the $4^{\text {th }}$ European Conference on Space Debris. ESA, 2005: 235242.

18. Nazarenko AI, Menchikov IL. Engineering model of space debris environment. Proceeding of the 3rd European Conference on Space Debris. ESA, 2001: 293298.

19. Christiansen EL, Lear D. Handbook for space shuttle meteoroid/orbital debris threat assessments (BUMPER). NASA/JSC-27471, 1996.

20. Lemcke C. Enhanced debris/micrometeoroid environment models and 3D software tools. Final Report, ESA CR (P) 4214, 1998.

21. O’Hara R, Jansen M. Overview of the NASA/JSC debris assessment software (DAS) - Version 1.5. Orbital Debris Quarterly News. 2001; 6(2): 5-6.

22. Martin CE, Cheese JE. Introducing the ESA DRAMA tool. IAC-04IAA.5.12.3.04. $55^{\text {th }}$ International Astronautical Congress, Vancouver Canada, 2004.

23. Reynolds RC. Documentation of program EVOLVE: A numerical model to compute projections of the man-made orbital debris environment. SPC Report No. OD91-002-U-CSP, System Planning Corporation, 1991.

24. Liou J-C, Hall DT, Krisko PH, et al. LEGEND - A three-dimensional LEO-toGEO debris evolutionary model. Advances in Space Research. 2004; 34(5): 981-986.

25. Anselmo L, Cordelli A, Jehn R, et al. New results of the upgraded SDM space debris modeling software. IAA.99-6.5.08. 50 ${ }^{\text {th }}$ International Astronautical Congress, Amsterdam The Netherlands, 1999.

26. Lewis HG, Swinerd GG, Ellis CS, et al. Response of the space debris environment to greenhouse cooling. Proceedings of the 4th European Conference on Space Debris. ESA, 2005: 243-248.

27. Martin C, Walker R, Klinkrad H. The sensitivity of the ESA DELTA model. Advances in Space Research. 2004; 34(5): 969-974.

28. NASA safety standard: guidelines and assessment procedures for limiting orbital debris. NSS 1740.14. NASA, 1995.

29. Lukjashchenko V, Yakovlev M, Chekalin S, et al. The status of Russian space debris mitigation standard. Proceedings of the $3^{\text {rd }}$ European Conference on Space Debris. ESA, 2001: 827-834.

30. Space debris mitigation standard. NASDA-STD-18A, March 1996.

31. Walker R, Martin C, Stokes H, et al. Update of the European space debris mitigation handbook - executive summary. ESA Contract 14471/00/D/HK. QinetiQ/KI/SPACE/CR021539, July 2002.

32. IADC space debris mitigation guidelines. Space Debris A/AC.105/C.1/L.260, UN COPUOS 40 ${ }^{\text {th }}$ session, Vienna Austria, 17-28 February 2003.

33. Technical report on space debris, A/AC.105/720, United Nations, New York, 1999.

34. Gruen E, Zook HA, Fechtig $\mathrm{H}$, et al. Collisional balance of the meteoritic complex. Icarus. 1985; 62(2): 244-272. 
35. Johnson NL, Whitlock DO, Anz-Meador PD. History of on-orbit satellite fragmentations. $13^{\text {th }}$ Edition, NASA/JSC 62530, Orbital Debris Program Office. 2004.

36. Johnson NL. History and consequences of on-orbit break-ups. Advances in Space Research. 1985; 5(2): 11-19.

37. McKnight DS. Determination of breakup initial conditions. AIAA 91-0299, $29^{\text {th }}$ Aerospace Sciences Meeting, Reno USA, 1991.

38. Kessler DJ, Matney MJ, Reynolds RC, et al. A search for a previously unknown source of orbital debris: the possibility of a coolant leak in radar ocean reconnaissance satellites. IAA-97-IAA.6.3.03. $48^{\text {th }}$ International Astronautical Congress, Turin Italy, 1997.

39. Sridharan R, Beavers W, Gaposchkin EM, et al. Radar and optical characterization of an anomalous orbital debris population. Journal of Spacecraft and Rockets. 1999; 36(5): 719-725.

40. Meshchreyakov SA. Physical characteristics of alkaline metals and behaviour of liquid metal coolant droplets occurring in near-earth orbits. Proceedings of the $2^{\text {nd }}$ European Conference on Space Debris. ESA, 1997: 257-260.

41. Foster JL, Krisko PH, Matney M, et al. NaK droplet source modeling. IAA-03IAA5.2.02, 54 ${ }^{\text {th }}$ International Aerospace Congress, Bremen Germany, 2003.

42. Wiedemann C, Oswald M, Stabroth S, et al. Size distribution of NaK droplets released during RORSAT reactor core ejection. Advances in Space Research. 2005: 35(7): 1290-1295.

43. Krisko PH, Foster JL. Modeling the sodium potassium droplet interactions with the low Earth orbit space debris environment. IAC-04-IAA.5.12.5-03. $55^{\text {th }}$ International Aerospace Congress, Vancouver Canada, 2004.

44. Jackson A, Eichler P, Reynolds R, et al. The historical contribution of solid rocket motors to the one centimeter debris population. Proceedings of the $2^{\text {nd }}$ European Conference on Space Debris. ESA, 1997: 279-284.

45. Ojakangas GW, Anderson BJ, Anz-Meador PD. Solid-rocket-motor contribution to large-particle orbital debris population. Journal of Spacecraft and Rockets. 1996; 33(4): 513-518.

46. Mulrooney M. An assessment of the role of solid rocket motors in the generation of orbital debris. NASA Internal Document, June 2004.

47. Bariteau M, Mandeville J-C. Modelling of ejecta as a space debris source. Space Debris. 2002; 2(2): 97-107.

48. Oswald M, Stabroth S, Wiedemann C, et al. Upgrade to the MASTER model. 18014/03/D/HK(SC), M05/MAS-FR, Rev. 1, April 2006.

49. Blagun V, Levitskiyi Yu, Kulik S. Activities on space debris in Russia. Proceedings of the 3rd European Conference on Space Debris. ESA, 2001: 2124.

50. Michal Th, Eglizeaud JP, Bouchard J. GRAVES: The new French system for space surveillance. Proceedings of the 4th European Conference on Space Debris. ESA, 2005: 61-66.

51. Donath T, Schildknecht T, Brousse P, et al. Proposal for a European space surveillance system. Proceedings of the $4^{\text {th }}$ European Conference on Space Debris. ESA, 2005: 31-38. 
52. Stansbery G, Foster JL. Completeness of measurements of the orbital debris environment. Proceedings of the 4th European Conference on Space Debris. ESA, 2005: 95-100.

53. Whitlock D. Modeling the effect of high solar activity on the orbital debris environment. Orbital Debris Quarterly News. 2006; 10(2): 4-5.

54. Johnson NL, Krisko PH, Liou J-C, et al. NASA'S new breakup model of EVOLVE 4.0, Advances in Space Research. 2001; 28(9): 1377-1384.

55. Hall DT. PROP3D - A long-term, intermediate-accuracy orbital element propagator for space debris studies. NASA Internal Document, May 2004.

56. Liou J-C. Collision activities in the future orbital debris environment. Advances in Space Research. 2006; 38(9): 2102-2106.

57. Krisko PH. Historical collisions in low earth orbit. IAC-06-B6.2.5, 57 ${ }^{\text {th }}$ International Astronautical Congress, Valencia Spain, 2006.

58. Johnson JL. private communication, 2007.

59. Krisko PH, Liou J-C. NASA Long-term orbital debris modeling comparison: LEGEND vs. EVOLVE. IAA-03-IAA.5.2.03. $54^{\text {th }}$ International Astronautical Congress, Bremen Germany, 2003.

60. Anon. A new collision in space?. Orbital Debris Quarterly News. 2002; 7(3): 12. 


\section{Captions for Tables}

Table 1: LEO Space debris source size ranges

Table 2: LEGEND parameters used in this study

Table 3: Test summary of average collision events with standard deviations

Table 4: Non-catastrophic small impactor on large target collision events

\section{Captions for Figures}

Figure 1. Debris flux vs. diameter as determined by multiple instruments and studies. (reproduced from Ref. [23])

Figure 2. Average (over 200 Monte Carlo iterations) collision rate over time during analysis period (1957 through 2035)

Figure 3. Average (over 200 Monte Carlo iterations) number of collisions by altitude bin at the end of the historical period, 2005, compared to the effective population of 1 $\mathrm{cm}$ and larger objects in the LEO altitude bins. (Effective number is defined and the portion of the orbit that passes through the altitude range.)

Figure 4. Average (over 200 Monte Carlo iterations) number of collisions by altitude bin at the end of the analysis period, 2035, compared to the effective population of 1 $\mathrm{cm}$ and larger objects in the LEO altitude bins. (Effective number is defined and the portion of the orbit that passes through the altitude range.)

Figure 5. Characteristic lengths of impactors and targets for all 200 Monte Carlo iterations in the study for years 1957 through 2035.

Figure 6. Masses of impactors and targets for all 200 Monte Carlo iterations in the study for years 1957 through 2035. 
Table 1: LEO Space debris source size ranges

\begin{tabular}{|l|l|l|l|l|}
\hline $\begin{array}{l}\text { Orbital debris } \\
\text { source }\end{array}$ & Size range & How observed & $\begin{array}{l}\text { Primary instrument } \\
\text { (United States) }\end{array}$ & $\begin{array}{l}\text { Estimated } \\
\text { number on- } \\
\text { orbit (2006AD) }\end{array}$ \\
\hline $\begin{array}{l}\text { Payloads and rocket } \\
\text { bodies past end-of-life }\end{array}$ & $>5 \mathrm{~cm}$ & $\begin{array}{l}\text { Tracked and } \\
\text { cataloged }\end{array}$ & SSN radars & 3600 \\
\hline Mission-related & $<1 \mathrm{~m}$ & $\begin{array}{l}\text { Tracked and } \\
\text { cataloged }\end{array}$ & SSN radars & 1270 \\
\hline $\begin{array}{l}\text { Fragments of on-orbit } \\
\text { explosions and } \\
\text { collisions }\end{array}$ & $<1 \mathrm{~m}$ & $\begin{array}{l}\text { Tracked and } \\
\text { cataloged, < } \\
\text { observed statistically }\end{array}$ & $\begin{array}{l}\text { SSN radars, } \\
\text { Haystack \& HAX } \\
\text { radars }\end{array}$ & $>1,000,000$ \\
\hline $\begin{array}{l}\text { Sodium potassium } \\
\text { coolant droplets }\end{array}$ & $\sim 1 \mathrm{~mm}$ to $5 \mathrm{~cm}$ & Observed statistically & $\begin{array}{l}\text { Haystack \& HAX } \\
\text { radars }\end{array}$ & $\sim 55,000$ \\
\hline $\begin{array}{l}\text { Solid rocket motor } \\
\text { char, slag, and dust }\end{array}$ & $\sim 100 \mu \mathrm{m}$ to $5 \mathrm{~cm}$ & Observed statistically & $\begin{array}{l}\text { Returned surfaces*, } \\
\text { ground-based tests }\end{array}$ & unknown \\
\hline $\begin{array}{l}\text { Ejecta and paint flakes } \\
\text { degradation products) }\end{array}$ & $<1 \mathrm{~mm}$ & Observed statistically & Returned surfaces* & unknown \\
\hline Meteoroids & $<1 \mathrm{~cm}$ & $\begin{array}{l}\text { Returned surfaces*, } \\
\text { ground-based optical } \\
\text { and radar measurements }\end{array}$ & unknown \\
\hline
\end{tabular}

* Space shuttle, ISS module, HST solar panels, Eureka \& LDEF surfaces 
Table 2: LEGEND parameters used in this study

\begin{tabular}{|c|c|}
\hline Parameter & 'Value' \\
\hline Region of space studied & LEO (200 km altitude through $2000 \mathrm{~km}$ altitude) \\
\hline Study period & 1957 through 2035 (79 years) \\
\hline Debris sources included & $\begin{array}{l}\text { Operational and spent payloads and rocket bodies } \\
\text { Mission-related debris (MRD) } \\
\text { Fragments (explosions and collisions) } \\
\text { Sodium potassium droplets (NaK) treated as solid }\end{array}$ \\
\hline Debris sources excluded & $\begin{array}{l}\text { Solid rocket motor slag }\left(\mathrm{Al}_{2} \mathrm{O}_{3}\right) \\
\text { Ejecta and paint flakes }\end{array}$ \\
\hline Traffic cycle for projection & 1999 through 2006 (8 years) cycled through 2035 \\
\hline Constellation spacecraft & $\begin{array}{l}\text { Launched in historical period only } \\
\text { Orbcomm stationkeeping 'off' at end-of-mission } \\
\text { Iridium perigee lowered to } 225 \mathrm{~km} \text { at end-of-mission } \\
\text { Globalstar re-orbited to } 1515 \mathrm{~km} \text { x } 1515 \mathrm{~km} \text { orbit }\end{array}$ \\
\hline Solar flux cycle for projection & $\begin{array}{l}\text { Repeated 11-year cycle based on curve fit of historical daily } \\
\text { measured flux [53] }\end{array}$ \\
\hline Excluded objects in launch file & $\begin{array}{l}\text { Space Shuttle, International Space Station, Progress vehicle, } \\
\text { mission-related debris associated with these crewed vehicles }\end{array}$ \\
\hline Operational spacecraft definition & $\begin{array}{l}\text { Constellation spacecraft }(\leq 8 \text { years in orbit) } \\
\text { Non-constellation spacecraft ( } \leq 5 \text { years in orbit) }\end{array}$ \\
\hline Mitigation measures applied & $\begin{array}{l}\text { Standard LEGEND future explosion rate based on recent past } \\
\text { activity } \\
\text { Collisional avoidance among operational constellation members } \\
\text { The 25-year guideline not explicitly applied }\end{array}$ \\
\hline $\begin{array}{l}\text { Monte Carlo iterations within } \\
\text { study period }\end{array}$ & 200 \\
\hline
\end{tabular}


Table 3: Test summary of average collision events with standard deviations

\begin{tabular}{|c|c|c|}
\hline Time period & $\begin{array}{l}\text { Historical period } \\
1957 \text { through } 2006 \\
\text { (50 years) }\end{array}$ & $\begin{array}{l}\text { Total period } \\
1957 \text { through } 2035 \\
\text { ( } 79 \text { years) }\end{array}$ \\
\hline $\begin{array}{c}\text { Ave \# collisions by impactor/target size } \\
\text { Target } \geq 10 \mathrm{~cm}, \text { Impactor } \geq 10 \mathrm{~cm} \\
\text { Target } \geq 10 \mathrm{~cm} \text {, Impactor }<10 \mathrm{~cm} \\
\text { Target }<10 \mathrm{~cm}, \text { Impactor }<10 \mathrm{~cm} \\
\end{array}$ & $\begin{array}{c}1.41 \\
27.67 \\
0.31 \\
\end{array}$ & $\begin{array}{r}5.03 \\
98.32 \\
1.18 \\
\end{array}$ \\
\hline $\begin{array}{l}\text { Ave \# collisions (All) } \\
\text { Catastrophic }\end{array}$ & $\begin{array}{r}29.39 \text { (StDev 5.05) } \\
1.63 \text { (StDev 2.19) }\end{array}$ & $\begin{array}{c}104.53 \text { (StDev 26.76) } \\
5.75 \text { (StDev 6.75) }\end{array}$ \\
\hline $\begin{array}{l}\text { Ave \# collisions (both objects } \geq 10 \mathrm{~cm} \text { ) } \\
\text { Catastrophic }\end{array}$ & $\begin{array}{l}1.41 \text { (StDev 1.21) } \\
0.89 \text { (StDev 0.95) }\end{array}$ & $\begin{array}{l}5.03 \text { (StDev 2.58) } \\
2.94 \text { (StDev 1.96) }\end{array}$ \\
\hline $\begin{array}{l}\text { Ave \# collisions }(\text { Target } \geq 10 \mathrm{~cm} \text {, Impactor }<10 \mathrm{~cm} \text { ) } \\
\text { Catastrophic }\end{array}$ & $\begin{array}{r}27.67(\text { StDev 4.88) } \\
0.45 \text { (StDev 0.70) }\end{array}$ & $\begin{array}{l}98.32 \text { (StDev 26.57) } \\
1.68 \text { (StDev 1.38) }\end{array}$ \\
\hline $\begin{array}{l}\text { Ave \# collisions (operational spacecraft) } \\
\text { Catastrophic }\end{array}$ & $\begin{array}{l}2.42 \text { (StDev 1.64) } \\
0.18 \text { (StDev 0.43) }\end{array}$ & $\begin{array}{l}5.02 \text { (StDev 2.49) } \\
0.30 \text { (StDev 0.57) }\end{array}$ \\
\hline $\begin{array}{l}\text { Ave \# collisions (NaK) } \\
\text { Catastrophic }\end{array}$ & $\begin{array}{l}4.48 \text { (StDev 1.87) } \\
0.15 \text { (StDev 0.37) }\end{array}$ & $\begin{array}{r}11.89 \text { (StDev 3.31) } \\
0.36 \text { (StDev 0.60) }\end{array}$ \\
\hline
\end{tabular}

Table 4. Non-Catastrophic small impactor on large target collision events

\begin{tabular}{|l|l|l|}
\hline Time period & $\begin{array}{l}\text { Historical period } \\
\text { 1957 through } 2006 \\
\text { (50 years) }\end{array}$ & $\begin{array}{l}\text { Total period } \\
\mathbf{1 9 5 7} \text { through } 2035 \\
\text { (79 years) }\end{array}$ \\
\hline Ave \# collisions & $27.22($ StDev 4.85) & $96.64($ StDev 24.00) \\
Target is intact (upper stage, spacecraft, MRD) & $25.34($ StDev 4.72) & $86.99($ StDev 19.85) \\
Target is operational (spacecraft) & $1.77($ StDev 1.33) & $4.16($ StDev 2.14) \\
\hline
\end{tabular}




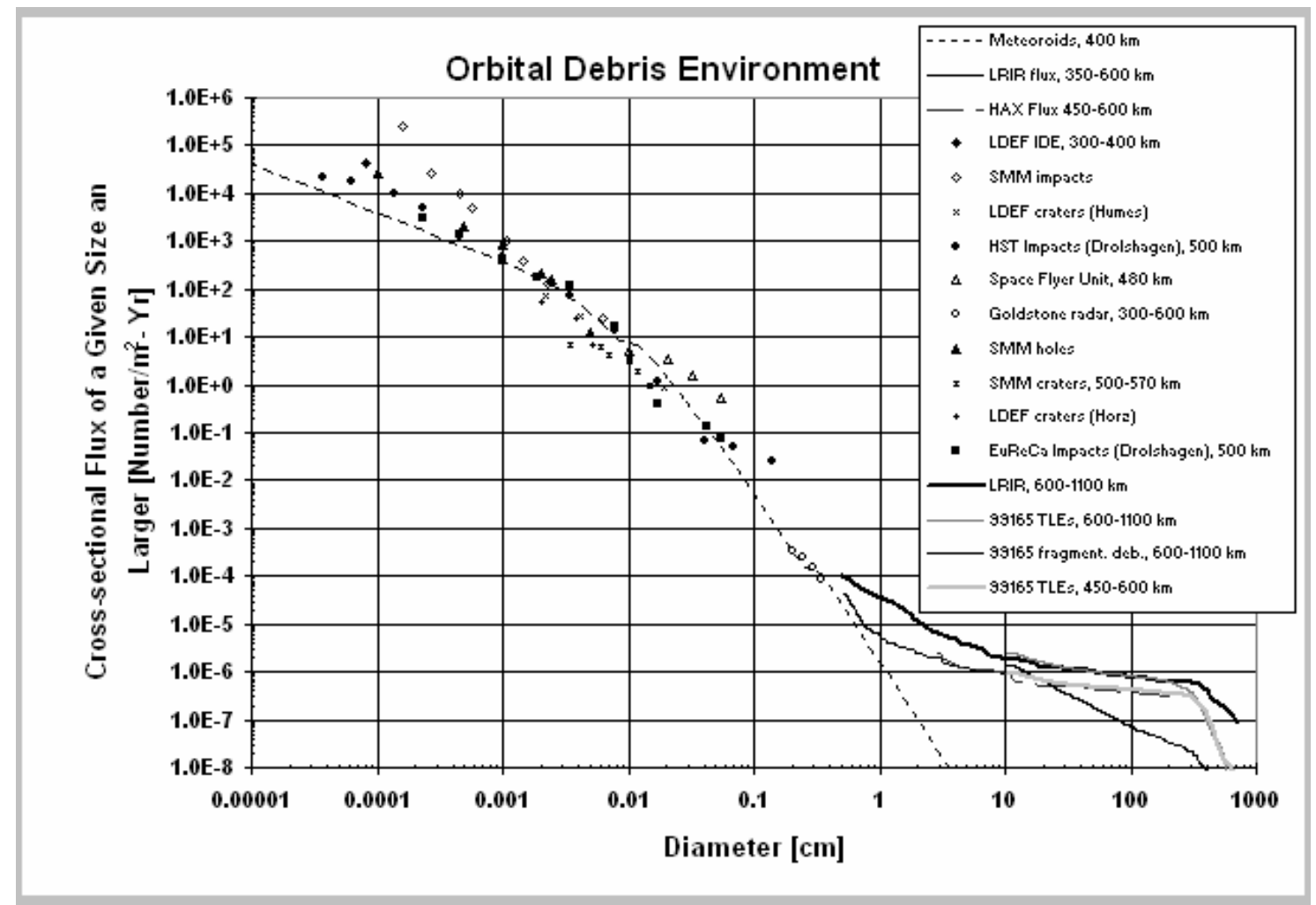

Figure 1.

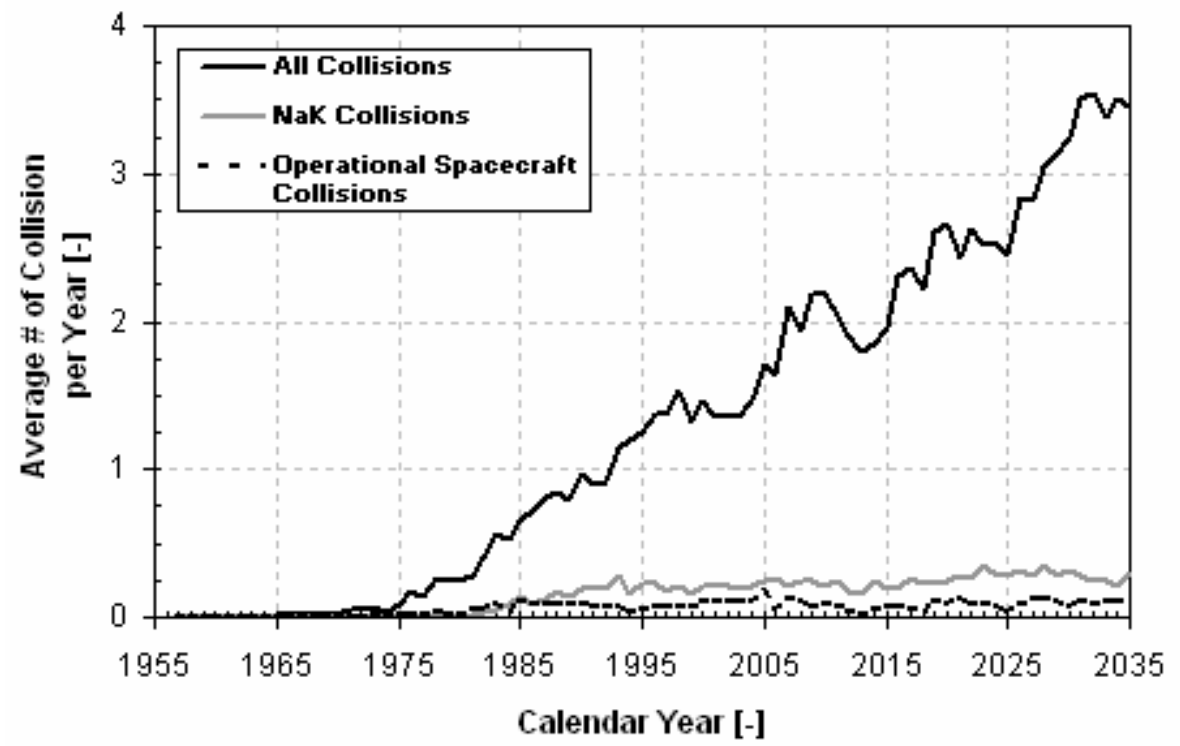

Figure 2. 


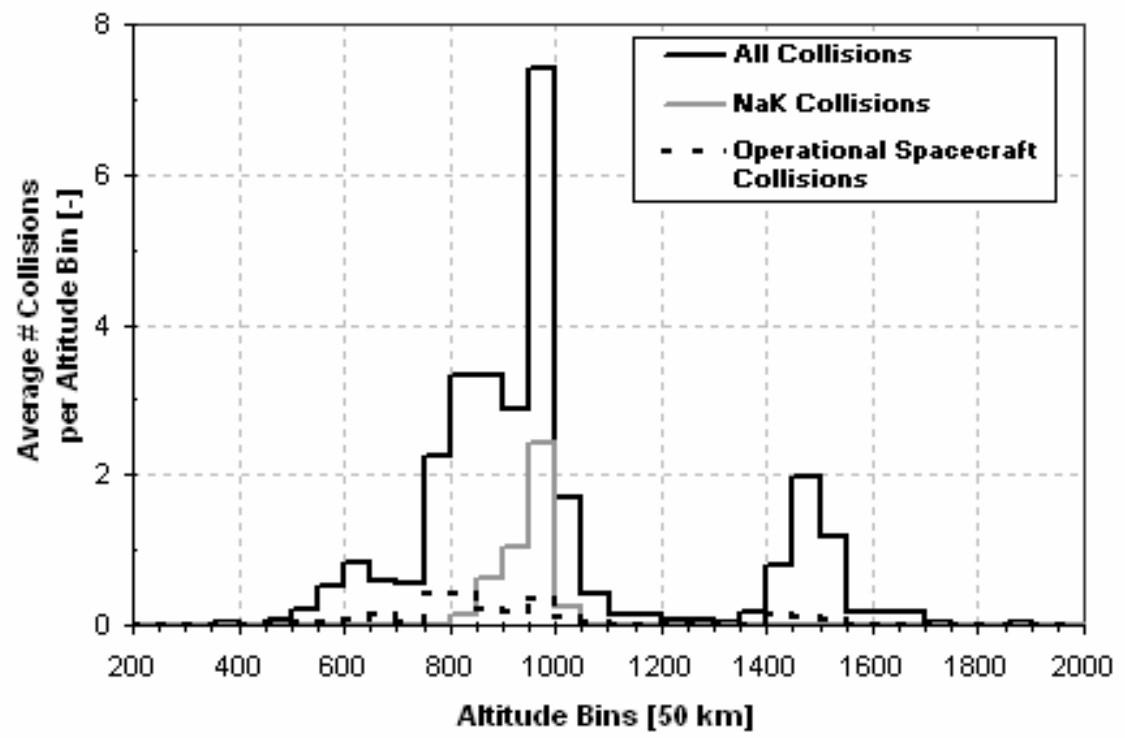

Figure 3.

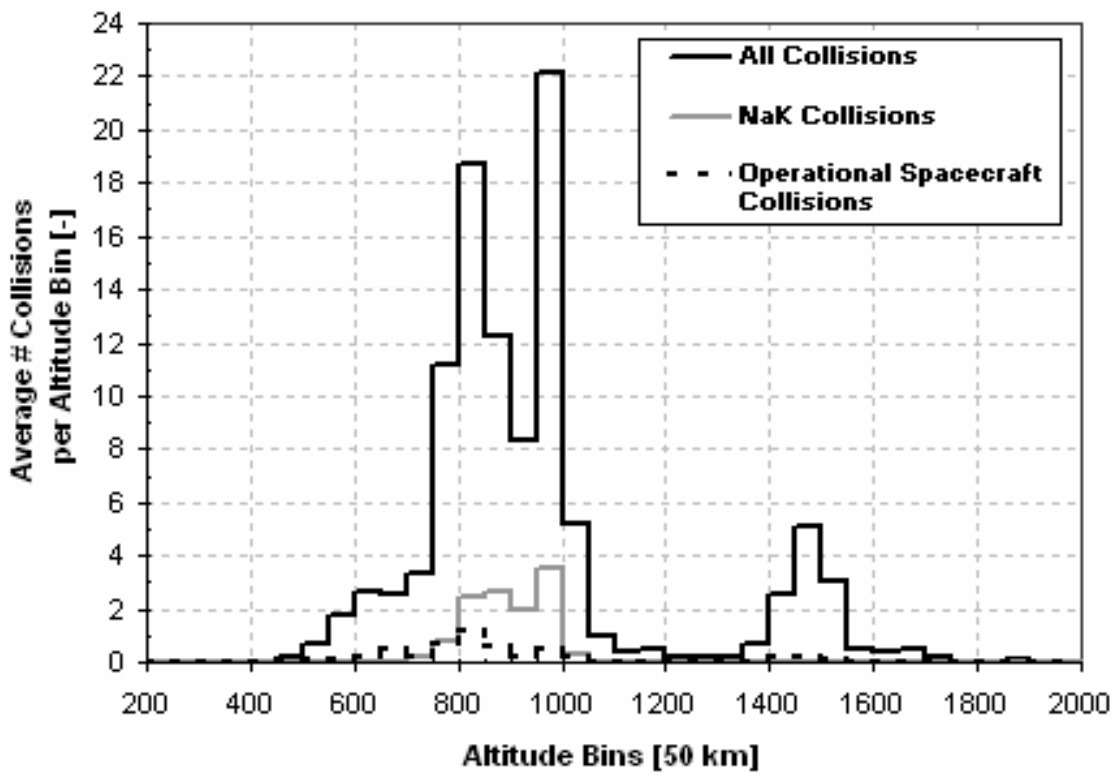

Figure 4. 


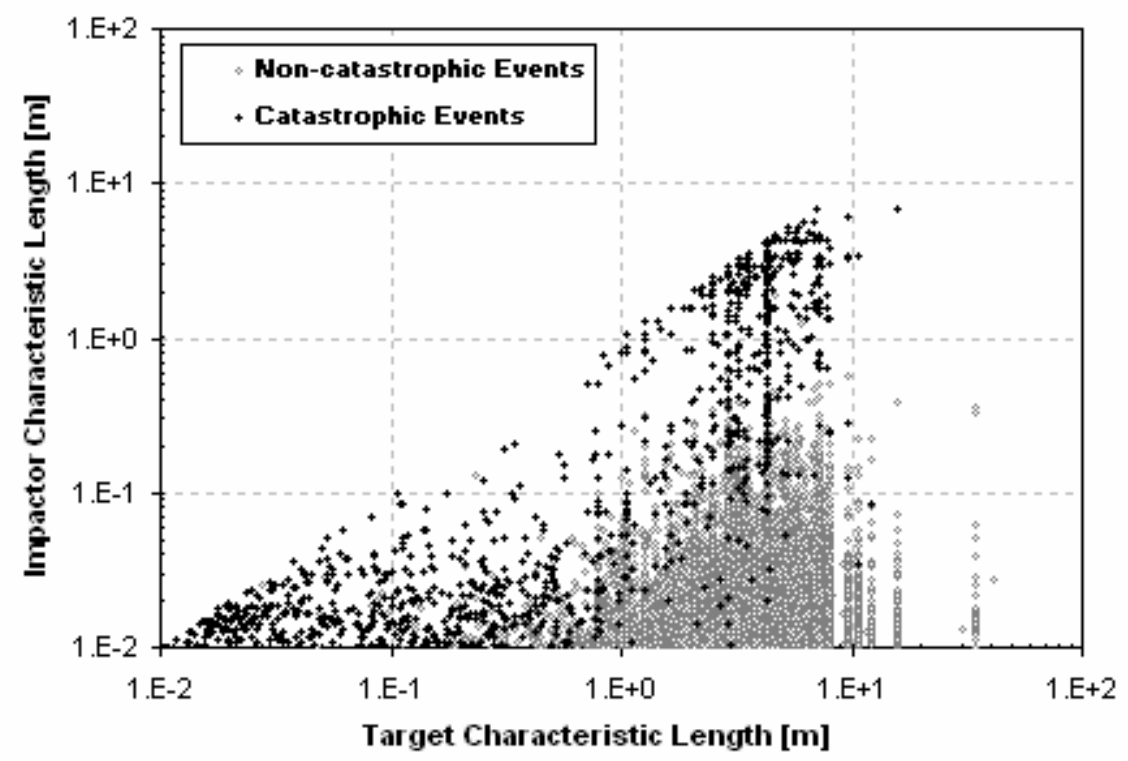

Figure5.

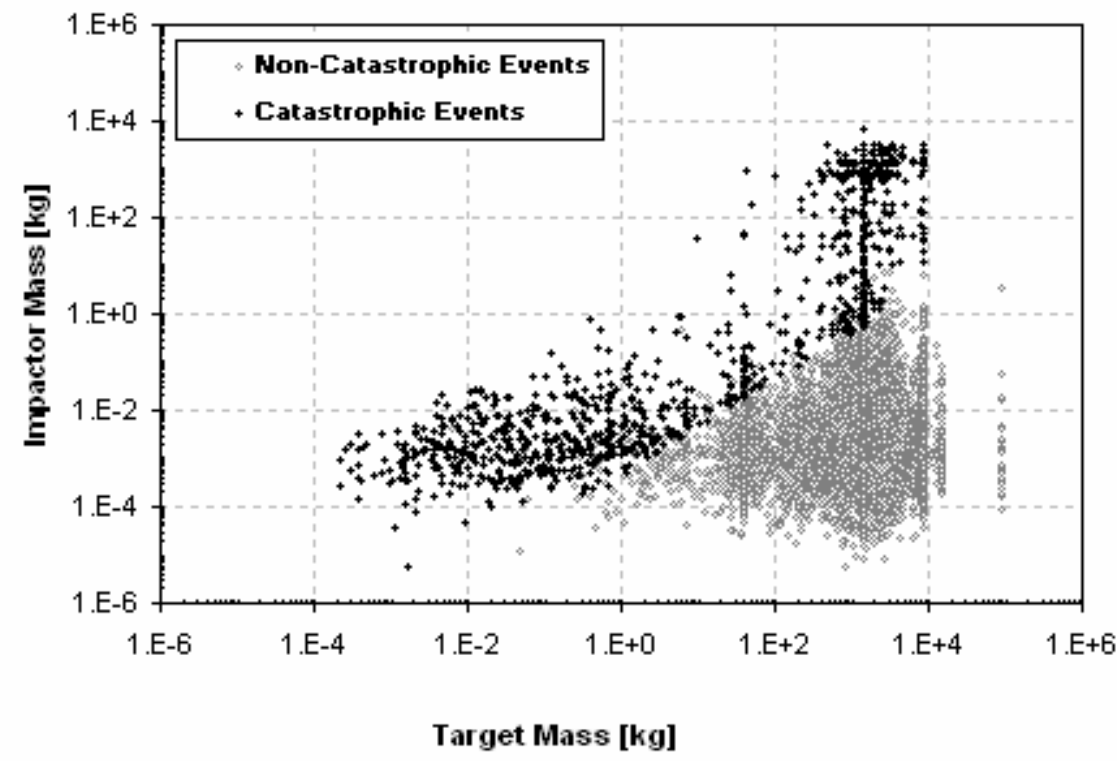

Figure 6. 